Stony Brook University

Academic Commons

2018

\title{
Library as Forum: Building Relationships and Identity through Faculty Speaker Events
}

Kathleen Kasten

State University of New York at Stony Brook, kathleen.kasten@stonybrook.edu

Follow this and additional works at: https://commons.library.stonybrook.edu/library_articles

Part of the Library and Information Science Commons

(c) (i) $(9)$

This work is licensed under a Creative Commons Attribution-Noncommercial-No Derivative Works 3.0 License.

\section{Recommended Citation}

Kasten, Kathleen, "Library as Forum: Building Relationships and Identity through Faculty Speaker Events" (2018). Library Faculty Publications. 40.

https://commons.library.stonybrook.edu/library_articles/40

This Article is brought to you for free and open access by the University Libraries at Academic Commons. It has been accepted for inclusion in Library Faculty Publications by an authorized administrator of Academic Commons. For more information, please contact mona.ramonetti@stonybrook.edu, hu.wang.2@stonybrook.edu. 


\begin{abstract}
The development of the liaison model in academic libraries has had important implications for the relationship between librarians and teaching faculty members. Modes of outreach to departments are conditioned by a variety of factors, and can have a profound effect on the library's image on campus. This case study describes and analyzes programming implemented at an academic library to position the library as a forum for interdisciplinary exchange on campus and as a platform for faculty research. This programming, conceived primarily as a series of speaker events, was created with an emphasis on research in the humanities and lettered social sciences in an effort to raise the profile of these disciplines at the library on a campus with an extensive focus on STEM fields. By partnering with these departments in order to create speaker-centric, discussion-focused programming, the library built relationships and fulfilled its responsibility to promote academic engagement.
\end{abstract}




\section{Introduction}

The development of the liaison model in academic libraries has had important implications for the relationship between librarians and teaching faculty members. Modes of outreach to departments are conditioned by a variety of factors, and can have a profound effect on the library's image on campus. As a fundamentally interdisciplinary space, the university library exists as a potential forum for intellectual inquiry, production, and exchange. In an era of scarce resources, the fulfillment of this role is rendered simultaneously problematic and increasingly vital as the library seeks to balance financial deficit with increasing diversity in patron needs and practices. Programming is a crucial means of branding the library as an intellectual nexus on campus, as well as a way to publicize emerging areas in research services and to create additional access points to physical and electronic collections. This paper describes the planning, advertisement, and organization of a series of faculty speaker events, with an emphasis on the cultivation of relationships between librarians and faculty members. Each event required collaboration between librarians and faculty, with the result of cultivating greater understanding on both sides of faculty research and librarian practice and expertise. Additionally, this paper examines the implications of this kind of outreach partnership for the role of the academic library as a cultural and intellectual nexus on campus, as well as the scholarly niche of the librarian as a colleague with faculty status. Through these events, librarians functioned as moderators and interlocutors in the research process on an equal footing with the researcher's other faculty colleagues.

Speaker-centric programming in the humanities and social sciences at Stony Brook University Libraries was envisioned with the objectives of consolidating the library's role as a center for scholarly production and conversation, of providing a platform for the dissemination 
of work and the identification of interdisciplinary connections, and of offering the campus community the opportunity to attend and participate in intellectual exchange based on faculty research. By placing the emphasis on the research process and the dissemination of work, these events mirror more traditional departmental colloquia as an activity capable of building and shaping a scholarly community. Likewise, librarians provided synthesis of discourses and ideas from diverse departments, inspiring faculty speakers and visitors to regard the library as a place of intellectual congress. Simultaneously, these events helped the campus community, and particularly the faculty, to see the libraries in a scholarly context. Unlike other forms of library outreach, these events focused on faculty contributions and emphasized the library as a partner in the research process, and librarians as scholars engaged in their own intellectual work. Each event focused on a faculty speaker, or a panel of three to four faculty speakers, who gave a talk on their current research. The lectures were open to the public, as well as to all members of the campus community. Each was followed by a rich discussion session. Though it is difficult to quantify the effect of this kind of programming, particularly from a perspective of academic engagement, it was possible to develop some evaluation metrics. These included the size and composition of the audience, the degree of audience engagement with the speaker, and the extent to which the program engendered follow-up conversations with the library.

Building on research on the academic library and its polyvalent historical relationship to faculty scholarship, this paper concludes that faculty-centered outreach through speaker events is an important bridge between the libraries and the campus. By situating the library-- as an entity made of collections, services, spaces, and people-- as a cultural locus, librarians have the opportunity to rethink the twentieth-century divide between librarians as practitioners and faculty members as researchers. 


\section{The liaison model and academic engagement}

The professional literature addresses both the role of the academic librarian within the liaison model, as well as the role of the library as a physical and intellectual space on campus. Discussion of the liaison model is multifaceted, particularly as the liaison model has developed to embrace emerging modes of scholarship and to cover larger portions of the research lifecycle. Indeed, recent scholarship by Ippoliti (2017) proposes a framework for understanding and implementing timely change in the liaison model.

Building on current scholarship, this paper situates speaker-centric programming within the context of academic library outreach, with respect for the liaison model as a conceptual framework for the relationship between academic librarians and the faculty, students, and staff that they serve. Likewise, research on the library as place is important in this context because it addresses the ways in which the physical library influences the valence of expectation held by the campus community. These two separate yet interrelated discourses provide a scholarly and practical framework within which to situate the development of faculty speaker series as a tool for outreach and academic engagement. Gibson and Coniglio (2010) describe the role of the liaison librarian, placing it in a historical context of librarians as bibliographers, custodians of collections, and research consultants. They further develop the idea of the modern liaison librarian as this role expands to embrace broader concepts within scholarly communication. The emerging emphasis on scholarly communication as a competency for liaison librarians has been studied by Brantley, Bruns, and Duffin (2017) and by Kenney (2015). Eldridge, Fraser, Simmonds, and Smyth have studied the development of the liaison role to include functional specializations (2016). This discourse is continued in Eddy and Solomon (2017), who explore the consultant role of the liaison in the context of a project intended to provide outreach related 
to open access and scholarly communication. This research has important implications for the creation of faculty speaker series, which allows liaison librarians to connect with faculty by providing a platform for research in progress, as well as finished research. This inscribes the librarian within the researcher's long term research program, allowing her to expand the presence of the library. Additionally, the professional literature addresses liaison work in partnership with university staff members in ways which have implications for speaker-centric programming. Wainwright and Davidson (2017) discuss liaison partnerships with non-academic entities on campus as a means of reaching students. Events in the humanities and social sciences at Stony Brook University Libraries have featured staff members as speakers. These events have been an excellent way to engage staff members from different departments and to build partnerships for future work.

The library as a physical, intellectual, and even imaginative space has also inspired pages of critical ink, including The library as place: History, community, and culture (eds. Buschman \& Leckie, 2007). This volume treats the library space as it has evolved over time, and explores the ways in which the library as place conditions how patrons use it, and the role that it plays in their research process. By emphasizing the continuing importance of the library as place, the chapters provide an important counterpoint to the notion that the library's future is exclusively digital. Similarly, faculty speaker series have the power to underscore the ways in which the physical library can serve as a platform for the dissemination of scholarly content. Shapiro (2016) argues that academic libraries can benefit from outreach and access policies at public libraries, including more work stations, marketing, and programming. He emphasizes the ways in which usages of physical space can influence, and be influenced by, the ways in which the academic library is conceptualized as an intellectual nexus. 
Fabian (2003) discusses speaker events in the context of a book talk series, placing them in a broader context with other kinds of programming, such as collections-based exhibits. By emphasizing the importance of building relationships with faculty members, Fabian considers the ways in which academic library outreach must grapple with issues of intellectual control and the image of the librarian as a research partner and scholar.

Strittmatter (2008) describes the benefits of hosting a cocktail party event for new faculty and departmental liaisons to the library. This essay engages with the budgetary and planning aspects of constructing such an event, with special consideration to the potential for strengthening faculty relationships with the library. Though speaker series are arguably a more formal version of academic library programming, they rely on similar notions of event planning and scholarly exchange among library and teaching faculty.

An article by Watson (2010) addresses the need for retail-style liaison services tailored to faculty in order to overcome the fact that the increase in electronically available library resources makes it potentially less likely that faculty will visit the library and come into contact with librarians. She describes an outreach program during which she scheduled individual meetings with faculty members. Following these visits, she noticed an apparent uptick in library engagement among these faculty, including greater responsiveness to email and other forms of library outreach. Though the speaker series discussed in this paper are in many ways the inverse of the kind of outreach described by Watson, they retain similar benefits of marketing the library to faculty members who may not otherwise visit the library or contact a librarian. Watson's emphasis on the need to be visible to faculty in order to get their attention virtually through email is borne out by the results of the faculty speaker series as well. Interestingly, Watson notes that the meetings seemed to inspire some faculty members to view librarians more as colleagues 
because they better understood the librarian's work and contributions. This is also reflected in the faculty speaker series.

Hankins (2009) discusses non-library conferences as another avenue by which academic librarians can come into contact with teaching faculty, and by which they may gain a greater understanding of the scholarly preoccupations and practices of their liaison areas. Citing Lyons (2007), she asserts that non-library conferences provide valuable context for librarians and help them to better perform their work in the library and on campus. This evidence of the need for contact between library and non-library faculty members underscores the value of bringing both of these overlapping communities together in the same scholarly space, such as an invited speaker event at the library. Hankins' article is a case study of a program at Texas A\&M University intended to support librarian attendance at non-library conferences. The speaker series discussed in the present paper helps to advance some of the same goals in a resource-light way.

The development of the liaison model as a framework for library outreach, research support, and collection management has had important benefits for library public service, as discussed in the resources cited above. However, librarians who have faculty status on their campuses still face challenges as they build relationships with the faculty in their liaison departments. Many liaisons work with multiple departments, creating problems with both time management and the ability to find librarians with adequate subject expertise. University departments function on scholarly training and specialization, which can present a barrier to liaison librarians who are not trained in the areas with which they liaise. That being said, their expertise in librarianship, as well as in emerging areas of liaisonship, such as scholarly communication, digital humanities, and research data management, provides an opportunity to 
engage with faculty in their liaison areas. Speaker-centric programming helps to bridge this gap by offering faculty speakers a platform for their work while simultaneously gaining greater insight into the needs of researchers in the fields that they support. Finally, speaker-centric programming requires librarians to work with faculty members over a period of months in order to plan the event. This is an opportunity to create a relationship with an individual scholar, or even with the scholar's department, which can facilitate the transmission of librarian expertise in research practices.

\section{Creating a forum}

The faculty speaker series at Stony Brook University Libraries is actually made up of several series organized by discipline or by theme and presented by various librarians. This essay focuses only on the events held in the disciplines of the humanities and social sciences, in honor of Women's History Month (March), Black History Month (February), and Hispanic Heritage Month (October), as well as events held to foster discussion about the Modern Language Association Convention. The decision to create programming around heritage months was complicated by a desire to avoid consolidating emphasis on a particular culture or theme into only one month to the detriment of the rest of the year. However, it was also recognized that heritage months offered the library a valuable opportunity to publicize its programming by linking with campus-wide events and initiatives for that month. These benefits seemed to outweigh the potentially problematic nature of heritage months, particularly since the creation of programming and collections could influence library services, collections, and policy throughout the year. Perhaps most importantly, the relationships created with faculty and students as a result of these speaker events were clearly seen to transcend the month in which they were held. 
The impetus of the speaker series was to celebrate and strengthen the library's role as a forum for interdisciplinary academic discourse on campus. This is particularly important in the context of the humanities and social sciences. Stony Brook University is strongly oriented toward STEM fields, rendering robust library support for the humanities and social sciences even more meaningful. Additionally, the speaker events were intended as a platform for research being performed by scholars on campus. Viewed as an extension of the liaison network, the speaker events sought to capitalize on what Gibson and Coniglio (2011, cited in Schlak, 2016) call the liaison's role as a "change agent." As the linchpin in an emerging system of library support, education, and engagement, Gibson and Coniglio's liaison librarian is ideally positioned to create a new identity for the librarian and for the library on campus. At Stony Brook University Libraries, we have endeavored to broaden the institution's profile within the arts, humanities, and social sciences. It has been crucial to establish the library as an essential part of the faculty research process. Though the responsibility to build engaging, rich collections remains a critical component of academic librarianship, the current budget situation faced by many libraries makes it untenable to consider this the library's sole place in academic research. Programming provides an opportunity to diversify this role. The faculty speaker series focuses on promoting research projects by providing a platform for campus speakers. This serves the intellectual purpose of inserting the library into every phase of the research lifecycle among the scholars it serves, including presentation, without requiring a budget for travel funding and honoraria for invited speakers. By limiting invitations to campus speakers, the library avoided this difficulty while fulfilling its mission to support research and learning on campus.

The notion of supporting both research and learning is a crucial one with regard to understanding the impact of faculty speaker events. In his treatment of the concept of social 
capital in the context of the liaison role in academic libraries, Schlak underscores the fact that outreach to faculty is in many important ways outreach to students (2016). Schlak makes his point in order to underscore the importance of cultivating relationships with faculty members in part to gain access to the "faculty-mediated environment" in which important parts of student learning occur (p. 411). This is an interesting lens through which to view faculty speaker events held at libraries, particularly as libraries look for new ways to integrate themselves into students' academic growth and experience. As both a platform for faculty research and a potential partner in the creation of this new knowledge, librarians have an opportunity to perform outreach to both faculty and students while helping to situate the faculty member's research directly within the student's intellectual experience. It is often the case that faculty members teach courses which are tangentially related to their own research agenda, or which may not be closely related at all. Because faculty are encouraged by the library to invite their students to any talks they give at the library, these events become a portal through which students can encounter elements of a faculty member's research which may never enter the classroom except implicitly. Additionally, students are inspired to view the library as more than a study space or repository for collections. Through speaker series, the library asserts its role as the intellectual heart of the campus, on which privileges the transformation of ideas into concretized scholarship which can be discussed and synthesized. This is, of course, a critical component of the kind of intellectual growth to which students are expected to aspire during and after their time at university. This is an important form of outreach on the part of the library, helping to establish it as a crucial nexus in both faculty research production and student intellectual development. 


\section{Procedure}

Each speaker event or panel was envisioned as a library-centric forum intended to celebrate faculty scholarship on campus, contributing to the library's reputation as a locus of intellectual activity and providing an opportunity for the campus community to engage with current scholarship. Speakers were identified through the author's knowledge of campus faculty and, where necessary, a careful search of the faculty pages of relevant departments' websites. As the event series gained visibility on campus, scholars volunteered to speak at the library and helped the author to identify other potential speakers. The author also worked with colleagues and liaison librarians to find scholars to invite. For each series, the goal was to invite speakers whose work was interdisciplinary or likely to be of interest outside of their home department, timely, and/or relevant to another area of study. For example, priority for Women's History Month speakers was given to researchers whose work emphasized both women's or gender studies, as well as another field which explored the idea of difference, alterity, or marginality. Very successful talks were given by scholars working at the intersection of gender studies and another area, such as work or disability studies.

Prior to the events, speakers were asked to provide a short biography, a title, and a twothree sentence summary of their talk. All of these elements were used to publicize the event, specifically through the creation of digital flyers to be used on the library website and in social media (Appendix A). Because the prompts sent in the initial invitation emails were intentionally vague in order to take advantage of faculty expertise, it was helpful to gain a clearer idea of the way in which the faculty member would present their research. Each event was publicized using the library's social media presence, as well as through campus-wide emails, digital signage, and with content on the library's website. 
Most events were designed as one-hour talks, including approximately fifteen minutes for discussion. However, the Women's History Month events in March 2017 included two panel presentations with multiple speakers. The panel format presented the advantage of placing research in an interdisciplinary, sometimes juxtapositional context. However, they also presented the problem of providing ample time for each speaker, in addition to affording adequate space for discussion. With speaker approval, most talks were recorded and photographed by the library's information technology group. The recordings are kept in a dark archive and made available upon request, while the photographs were used in library social media and on the library's blog.

\section{Results}

It is difficult to choose an appropriate metric by which to measure the intellectual and outreach impact of a speaker event held at an academic library, primarily because the most easily measured element, the number of people in attendance, is not necessarily indicative of the nature or the extent of that impact. Nearly all of the speaker events held in the arts, humanities, and social sciences at Stony Brook University Libraries since March 2016 have been attended by an eclectic mix of faculty (library and teaching), staff, students, and community members.

An additional benefit of these series was to impact the image of the librarian among the teaching faculty. At Stony Brook University, librarians have faculty status and are eligible for tenure. However, misperceptions about this status are common among non-library faculty. Faculty speaker series, though intended to highlight the research activities of the teaching faculty, encourage non-library faculty to better understand the ways in which librarians contribute to the research process as resources and as partners. By providing a platform for faculty work, librarians position themselves as active partners in the dissemination and 
discussion of intellectual endeavor on campus. This multi-stage involvement is crucial at a time when key aspects of the role of the academic librarian are in a state of constant evolution and enrichment. Academic librarians have traditionally offered expertise in information literacy, as well as in primary and secondary research. Teaching researchers and students how to find, evaluate, synthesize, and responsibly cite information resources has been one of the foundations of the relationship between the academic librarian and the community she serves. It is well reflected in the current liaison-based models of library public service. Libraries enhance the services they can provide, as well as their own subject expertise, by forming close relationships with scholars and students working in particular areas. This, in turn, informs the ways in which librarians understand the unique needs, priorities, and preoccupations of these researchers. In this way, research support and information literacy function as vital methods of understanding and supporting the diverse communities of inquiry which populate the modern university. These library competencies pair well with emerging areas, such as research data management and scholarly communication, both of which build on the librarian's knowledge of the research development process and the ways in which academic work is created, disseminated, and consumed. Faculty speaker events at academic libraries provide a coda to this process, allowing librarians to enhance and participate in the scholarly community that they help to create on their campuses.

The establishment of the library as a locus for the dissemination of scholarly research through speaker series finds a counterpoint in the creation of institutional repositories to house and make accessible faculty research. At Stony Brook University Libraries, faculty speaker events are recorded and the link to the recording is made available upon request. This has been particularly valuable to several speakers, particularly those interested in developing their skills 
and profiles as public intellectuals. The library is delighted to serve in this capacity, and to play a role in contributing to the expansion of a researcher's platform.

There were also numerous benefits for faculty speakers, many of whom have been earlycareer professors working on the research that they will use to pursue tenure. For them, library speaker events afford them the opportunity to develop as public intellectuals if they choose, to reach a broader audience, to present works in progress, and to cultivate a closer relationship to the library.

Event attendees, particularly students, have the opportunity to access faculty expertise outside the classroom, and to interact with faculty members both as speakers and as fellow attendees. This is important because it creates community in a way that is fundamentally different from the classroom. Wainwright and Davidson (2017) note the library's potential as a neutral space on campus, capable of facilitating a different kind of interaction. Graduate student attendees at library events encounter faculty outside their programs, leading to new potential connections. Finally, speaker events at the library are an opportunity to engage the community outside the university, as well as personnel from surrounding institutions, as well as campus staff members. This is especially important because some events have featured staff members as speakers, to great acclaim, which is an important contribution to the creation of community on campus.

\section{Conclusions}

The speaker series format offers the benefit of providing a flexible, iterative context for academic library outreach. Because of their resource-light planning process, they offer the library an opportunity to expand its presence on campus and to function as a locus for scholarly inquiry and exchange. This positions the library within the institution as a center for the 
creation, presentation, and discussion of research, locating it at the intellectual core of the campus. Speaker-centric programming underscores the library as both place and concept within the larger institution, permitting a reassertion of its vital role in the modern university landscape. Future directions for the series in the arts, humanities, and lettered social sciences include applying for grant funding to support invitations to outside speakers. This offers the triple benefit of providing an additional dimension to library programming with regard to speaker events, of positioning the library as a venue at which faculty and students can encounter outside scholarship on campus, as well as raising the profile of library speaker events. Although this contradicts the original intent to showcase research by campus scholars, it offers the additional benefit of expanding the intellectual conversation with the library as a central figure.

Additionally, future speaker events could be designed to better showcase staff expertise within and outside of the library. Past speaker events have included staff members as speakers. This is an important opportunity to diversify the conversation on campus and to position the library as a locus of speech, discussion, and communication. The faculty speaker series is a flexible format capable of enhancing library presence and creating a nexus of scholarly communication and intellectual exchange on campus. 


\section{References}

Brantley, S., Bruns T. A., \& Duffin, K. I. (2017) Librarians in transition: Scholarly communication support as a developing core competency. Journal of Electronic Resources Librarianship 29(3): 137-150. DOI: 10.1080/1941126X.2017.1340718

Buschman, J. E. \& Leckie, G. J. (2007). The library as place: History, community, and culture. Wesport, CT: Libraries Unlimited.

Eddy, M. A. \& Solomon, D. (Mar 2017). Leveraging librarian liaison expertise in a new consultancy role. Journal of Academic Librarianship 43(2): 121-127. DOI: 10.1016/j.acalib.2017.01.001

Eldridge, J., Fraser, K., Simmonds, T., \& Smyth N. (2016). Strategic engagement: New models of relationship management for academic librarians. New Review of Academic Librarianship 22(2-3): 160-175. DOI: 10.1080/13614533.2016.1193033

Fabian, C. A., D’Aniello, C., Tysick, C., \& Morin, M. (2003). Multiple models for library outreach initiatives. The Reference Librarian 82: 39-55. DOI: 10.1300/J120v39n82_04

Gibson, C. \& Coniglio, J. W. (2010). The new liaison librarian: Competencies for the 21st century academic library. The expert library: Staffing, sustaining, and advancing the academic library in the 21 st century. Eds. S. Walter \& K. Williams. Chicago: Association of College and Research Libraries, pp. 93-126.

Hankins, R. (2009). Meeting our users where they conference: A Texas A\&M Model to Support Librarian Attendance at Subject-Specific Conferences. Public Services Quarterly 5: 98-113. DOI: $10.1080 / 15228950902837541$

Ippoliti, C. (Oct 2017). Extreme makeover: A blueprint for redefining the role of the liaison 
librarian in the academic library. International Information \& Library Review 49(4): 304309. DOI: $10.1080 / 10572317.2017 .1383743$

Kenney, A. R. (2015). From engaging liaison librarians to engaging communities. College \& Research Libraries 76(3): 386-91.

Lyons, L. E. (2007). The dilemma for academic librarians with collection development responsibilities: A comparison of the value of attending library conferences versus academic conferences. Journal of Academic Librarianship 33(2), $180-189$.

Schlak, T. (2016). Social capital as operative in liaison librarianship: Librarian participants' experiences of faculty engagement as academic library liaisons. The Journal of Academic Librarianship 42: 411-22.

Shapiro, S. D. (2016). Engaging a wider community: The academic library as a center for creativity, discovery, and collaboration. New Review of Academic Librarianship 22(1): 24-42.

Strittmatter, C. (2008). If you pour it, they will come: Hosting a cocktail reception to promote services to faculty. Public Services Quarterly 4(3): 269-76. DOI: $10 / 1080 / 15228950802128777$

Wainwright, A. \& Davidson, C. (2017). Academic libraries and non-academic departments: A survey and case studies on liaising outside the box. Collaborative Librarianship 9(2): 117-134.

Watson, E. M. (2010). Taking the mountain to Mohammed: The effect of librarian visits to faculty members on their use of the library. New Review of Academic Librarianship 16: 145-59. DOI: 10.1080/13614533.2010.500922 


\section{Appendix A}

\section{After Identity \\ Migration, Critique, Italian American Culture}

A Book Talk by Dr. Peter Carravetta Alfonse M. D'Amato Professor in Italian \& Italian American Studies

February 7, 2018 • 12:00pm • Melville Library E-2340

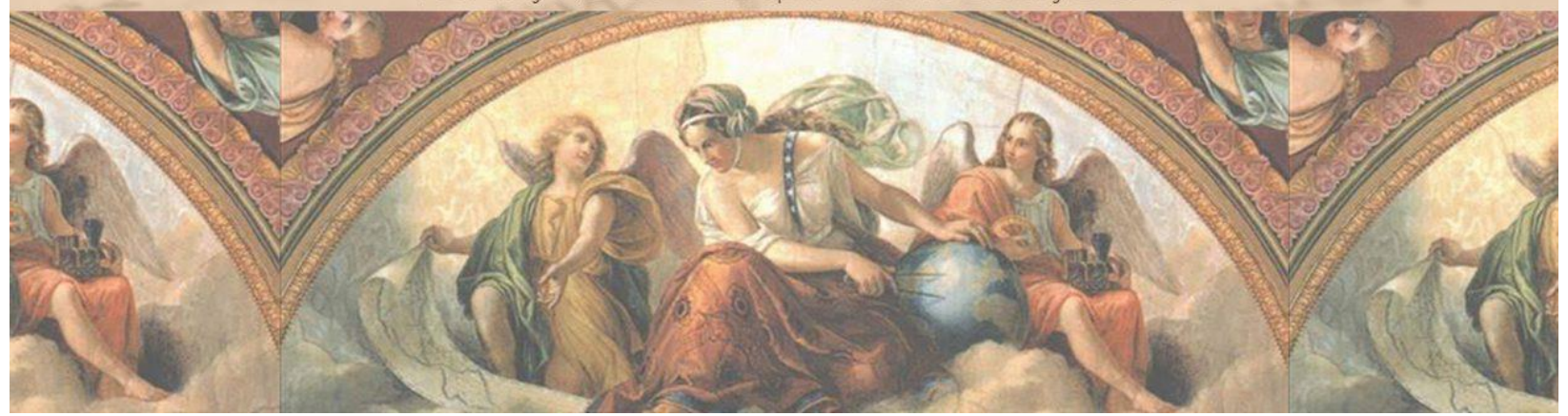

\section{ALFRED D'ESCRAGNOLLE TAUNAY AND THE PARAGUAYAN WAR}

\section{Dr. Javier Uriarte}

Department of Hispanic Languages and Literatures

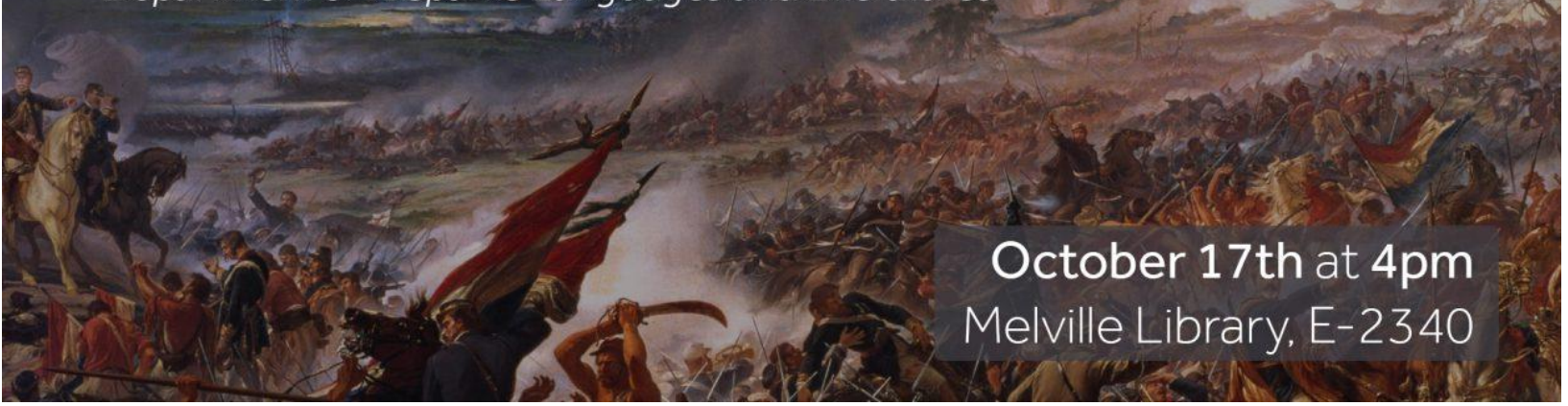

Graphics created by Dana Haugh, Stony Brook University Libraries, reproduced with kind permission. Except where otherwise noted, this work by SBU Libraries is licensed under a Creative Commons Attribution-NonCommercial 4.0 International License. 